Parental care-giving and home environment predicting offspring's temperament and character traits after 18 years

\title{
Josefsson, Kim
}

2013-10-30

Josefsson, K, Jokela , M , Hintsanen, M , Cloninger , C R , Pulkki-Raback , L, Merjonen , $P$, Hutri-Kahonen , N \& Keltikangas-Jarvinen , L 2013 , ' Parental care-giving and home environment predicting offspring's temperament and character traits after 18 years ' ,

Psychiatry Research, vol. 209 , no. 3 , pp. 643-651 . https://doi.org/10.1016/j.psychres.2013.01.007

http://hdl.handle.net/10138/42140

https://doi.org/10.1016/j.psychres.2013.01.007

acceptedVersion

Downloaded from Helda, University of Helsinki institutional repository.

This is an electronic reprint of the original article.

This reprint may differ from the original in pagination and typographic detail.

Please cite the original version. 


\title{
Parental care-giving and home environment predicting offspring's temperament and character traits after 18 years
}

\author{
Kim Josefsson ${ }^{\text {a,* }}$ \\ Markus Jokela $^{\mathrm{a}}$ \\ Mirka Hintsanen ${ }^{\mathrm{b}}$ \\ C. Robert Cloninger ${ }^{\mathrm{c}}$ \\ Laura Pulkki-Råback ${ }^{\mathrm{a}}$ \\ Päivi Merjonen ${ }^{\mathrm{a}, \mathrm{d}}$ \\ Nina Hutri-Kähönen ${ }^{\mathrm{e}}$ \\ Liisa Keltikangas-Järvinen $^{\mathrm{a}}$
}

a) IBS, Unit of Personality, Work, and Health Psychology, University of Helsinki, Finland

b) Helsinki Collegium for Advanced Studies, University of Helsinki

c) Washington University School of Medicine, St. Louis, USA

d) Department of Biological Psychology, VU University Amsterdam, The Netherlands

e) Department of Pediatrics, University of Tampere, and Tampere University Hospital, Tampere, Finland.

*) Corresponding author: Kim Josefsson, Siltavuorenpenger 1 A, P.O.Box 9, 00014

University of Helsinki, Finland, email: kim.josefsson@helsinki.fi, phone: +35891912 9545, fax: +358919129251 


\begin{abstract}
Although many personality theories emphasize the role of parental behaviors in shaping personality development, empirical data from longitudinal studies remains scarce. It is also not known, if parental behaviors affect character development more strongly than temperament or vice versa. In a prospective study, 1083 volunteer participants of the Young Finns study completed the Temperament and Character Inventory (TCI). Parents of the participants had answered questions about parenting attitudes, socioeconomic status, health behaviors, and role satisfaction 18 years before. We studied the univariate and the cumulative effects of parental care-giving and family environment on offspring's personality traits. Parental care-giving and home-environment were more strongly associated with offspring character traits reflecting personality maturity (Self-directedness and Cooperativeness) than with offspring temperament traits (Novelty seeking, Harm avoidance, Reward dependence and Persistence) reflecting emotional and behavioral tendencies. The differences were most evident in the cumulative effects model. Maternal variables were stronger predictors than paternal variables. The present findings suggest that not all personality traits are similarly predicted by parental care-giving and home-environment. In particular, character development is more strongly related to such measures than temperament. Parental caregiving and home-environment are more strongly related to psychological maturity (character) than emotional and behavioral tendencies (temperament).
\end{abstract}

KEY WORDS: parenting, TCI, personality development, personality, longitudinal, prospective, psychobiological 


\section{Introduction}

There is a long tradition of studying how parenting and family environment are related to child development ( Baumrind, 1967; Bowlby, 1969; Ainsworth et al., 1978). Recent theorizing has concentrated particularly on the difference between normal or "good-enough parenting" versus pathological variation in the rearing environment (Maccoby, 2000). The adverse effects of severe environmental deprivation and parental maltreatment on abnormal child development have been demonstrated. The influence of non-pathological variation in parental behaviors, on the other hand, is still debated (Scarr, 1992). The present study examines how characteristics of the early developmental environment in childhood and adolescence predict temperament and character traits in adulthood.

\subsection{Early environment and development}

Non-pathological differences in rearing environments can be delineated by considering the basic needs of children. Such common basic needs include physical needs (e.g., food and health care), need for stable family environment (e.g., no violence, no family conflict, stable caregiver relationship), and need for guidance and support (e.g., emotional support, parental structure, and cognitive stimulation) (Dubowitz et al., 2005).

Children whose basic needs are not adequately met are considered to be neglected (Dubowitz et al., 2005). Thus, a neglectful environment is defined as a deficiency of appropriate parenting behavior whether or not more severe aspects of inappropriate parenting, such as abuse, are present (Schumacher et al., 2001). Although appearing less severe, neglect can cause adverse consequences comparable to physical and sexual abuse or domestic violence (Hildyard and Wolfe, 2002).

Dysfunctional family environments do not provide children many of the experiences that are necessary for normal development and adaptation (Cicchetti and Toth, 2005). 
Repeated developmental disruptions caused by unsupportive environment can lead to relatively enduring vulnerability that increases the probability of further developmental disruptions (Cicchetti, 2004; Cicchetti and Toth, 2005). Even normal developmental tasks may challenge children, if important developmental milestones are not achieved (Maughan and McCarthy, 1997; Hildyard and Wolfe, 2002; Cicchetti and Toth, 2005). Children growing up in an environment failing to provide consistent and appropriate opportunities for development are more likely to internalize negative self-perceptions or self-schemas which, in turn, increase the risk of adult psychopathology, especially that of anxiety and depression (Brewin et al., 1993; Schilling et al., 2007; Tyrka et al., 2009; Scott et al., 2010).

Human development and transmission of behaviors from parents to offspring is also affected by genetic factors (Harris, 1995; Collins et al., 2000; Caspi et al., 2004). Twin studies suggest only a modest role for shared environment in the resemblance of biological relatives in many psychological traits. However, some of the specific associations between parenting and child development appear to be environmentally rather than solely genetically mediated. For example, father-infant and mother-infant attachment security is strongly explained by environmental factors (Bokhorst et al., 2003; Bakermans-Kranenburg et al., 2004; Roisman and Fraley, 2006). Furthermore, mother's expressed emotion and emotional attitudes have been shown to predict child's antisocial behavior even when the shared genetic background of mothers and offspring has been taken into account (Caspi et al., 2004). Evidence from behavior-changing interventions focusing on parental behavior also suggests that changes in parental behavior are accompanied by changes in the behavior of the (untreated) children (Anisman et al., 1998; Collins et al., 2000). The influence of parental behavior on socioemotional development of offspring has also been observed in experimental animal studies (Meaney, 2001; Zhang and Meaney, 2010). 


\subsection{Personality as an indicator of adaptive development}

Personality reflects the coherence of behavior and emotions, and adaptation of the individual to the environment. In this study, we use the psychobiological model of personality developed by Robert Cloninger and colleagues (1993) to examine the relationship between parental care-giving and family-environment in childhood and personality in adulthood. The psychobiological theory of personality (Cloninger, 2008) postulates that personality is composed of temperament and character, two inter-related domains which are hypothesized to interact as a non-linear dynamic system regulating the development of human psychological functions. Temperament traits become manifested early in life and reflect biases in automatic responses to emotional stimuli, whereas character traits depict differences in higher cognitive functions underlying a person's goals and values (Cloninger et al., 1993). Temperament involves involuntary emotional processes, whereas character involves voluntary rational processes (Cloninger, 2008). Temperament and character are considered to interact dynamically in the development of personality across the lifespan (Cloninger et al., 1997; Cloninger, 2008). Immature character has important psychopathological consequences and is typical of individuals with most forms of psychopathology, including mood disorders, depressive symptoms, schizophrenia, substance dependence, and personality disorders (Cloninger et al., 2010; Josefsson et al., 2011).

\subsection{Cumulative nature of environmental risks}

Most children with only one risk factor follow a normal and healthy developmental path (Sabates and Dex, 2012). A large number of accumulated risk factors seems to be the best predictor of negative developmental outcomes, regardless of which specific risk factors occur together (Sameroff et al., 1987; Evans, 2003; Atzaba- Poria et al., 2004; Flouri, 2008; Sabates and Dex, 2012). A cumulative risk factor model may be the best choice because it reflects the 
typical natural covariation of many childhood risk factors (Evans, 2003). Due to this rather strong covariation, the independent effects of single risk factors are usually small. A cumulative model captures the complex dynamics of risk factors better than models based on independent effects. A cumulative risk index is also more stable than any individual risk measure alone (Flouri, 2008). This helps in establishing plausible causal pathways between childhood risks and adulthood outcomes.

\subsection{Current study}

The present study examines whether parental care-giving and home-environment assessed in a prospective population-based sample predict offspring's personality in adulthood assessed 18 years later. We explore both the effects of single parental variables independently and the cumulative effect of several parental variables. The study design is prospective with parentreported data on childhood and adolescence environments at baseline and self-reported data on personality 18 years later. The parental variables included in the study (care-giving, socioeconomical status (SES), age, unhealthy habits, dissatisfaction) are associated with important broad family context factors that can influence child development via learning, emotional climate of the family and parental expectations of their children (Sheffield Morris et al., 2007).

Current evidence on the persistence of the effects of childhood environment into adulthood personality is very limited (Mersky and Topitzes, 2010). Most of these studies have been based on retrospective recollections of childhood environment (Reti et al., 2002; Oshino et al., 2007). These studies suggest that retrospectively reported adverse parental behaviors correlate modestly with high neuroticism and low conscientiousness (Mccrae and Costa, 1988; Hojat and Borenstein, 1990; Lundberg et al., 1999). In retrospective studies using TCI, negative parental behaviors have been associated with high Harm avoidance and 
low Self-directedness in adulthood (Schlette et al., 1998; Reti et al., 2002; Oshino et al., 2007; Takeuchi et al., 2011). Some studies have found associations with low Reward dependence (Schlette et al., 1998), low Cooperativeness (Schlette et al., 1998; Takeuchi et al., 2011), low Persistence (Takeuchi et al., 2011), and low Self-transcendence (Takeuchi et al., 2011). However, these studies are subject to recall and common informant biases, i.e. people with different personalities may remember or perceive their childhood experiences differently.

By definition, temperament is influenced less by sociocultural learning than character (Cloninger, 1994a). In addition, both high and low extremes of each temperament trait can be advantageous or disadvantageous depending on the situational context (Cloninger et al., 1993). In comparison, maturity of character (high Self-directedness, high Cooperativeness) is culturally preferred to immaturity of character (low Self-directedness, low Cooperativeness) because a mature character is advantageous in most life situations. Previous research also suggests that childhood family environment may be more strongly related to psychological maturity than to behavioral-emotional aspects of personality (BrooksGunn and Duncan, 1997; Nakao et al., 2000). Thus, the associations of parental care-giving and home environment with temperament traits (Novelty seeking, Harm avoidance, Reward dependence, Persistence) are expected to be weaker than the corresponding associations with the character traits (Self-directedness, Cooperativeness, Self-transcendence).

Most parental variables are not expected to be associated with Novelty seeking that is characterized by initiation of activity whether it is to approach something pleasant (good family environment) or to get away from something unpleasant (bad family environment) (Cloninger, 1994b). Offspring's Novelty seeking may be associated with parental unhealthy habits, however, since badly functioning families may increase offspring's vulnerability to substance abuse and substance abuse has been shown to be associated with high Novelty 
seeking (Repetti et al., 2002; Cloninger et al., 2010). Family environment and care-giving are expected to be associated with Harm avoidance because adapting to threatening and stressful circumstances may lead to increased readiness to perceive and respond to threats (high Harm avoidance) (Repetti et al., 2011; Taylor et al., 2011). Reward dependence gives the will to maintain social affiliation despite intermittent social disapproval and approval so it is not expected to be strongly associated with care-giving and family environment (Cloninger, 1994b). However, in a very stressful family environment it may be adaptive to have low Reward dependence as a trade-off between being less stressed and being socially connected. Persistence is expected to be associated with family socioeconomic status since welleducated and wealthy parents usually encourage their children to follow their footsteps, and this encouragement is expected to lead to higher Persistence which helps in studying and working hard. However, persistent people can feel both well and ill. Anorexic and obsessivecompulsive people, for example, are highly persistent as are often successful businessmen (Cloninger et al., 2010). Therefore, family environment, as a whole, is not expected to be strongly associated with Persistence.

Self-directedness is the extent to which a person identifies the self as an autonomous individual and Cooperativeness expresses empathy and identification with other people (Cloninger et al., 1993). Care-giving and family-environment are expected to be associated with Self-directedness and Cooperativeness because, in Western cultures, most parents and the society aim at socializing children to be autonomous (high Self-directedness), independent (high Self-directedness), and responsible towards other people (high Cooperativeness) (Keller et al., 2006; Tulviste et al., 2007). Also, early adversity may produce deficits in emotion regulation (low Self-directedness) and social functioning (low Cooperativeness) (Repetti et al., 2011; Taylor et al., 2011). Self-transcendence involves selfawareness of being an integral part of the unity of all things (Cloninger et al., 1993). It is not 
expected to be associated with childhood family environment because it is not related to the concepts of self and social relationships which are most central in care-giving and familyenvironment. We also expect that a combination of different parental variables is a better predictor of offspring's personality traits than single variables because an accumulation of several risk-factors poses a greater stress to a child than single risk factors.

\section{Methods}

\subsection{Participants}

The Young Finns Study started in 1980. The subjects for the original sample in 1980 $(\mathrm{N}=3596)$ were selected randomly from six different age cohorts in the population register of the Social Insurance Institution, a database covering the whole population of Finland. The design of the study and the selection of the sample have been described in detail by Raitakari et al. (Raitakari et al., 2008). The measurements for the present study were carried out in 1983 and 2001. In 2001, the cohorts were 24, 27, 30, 33, 36 and 39 years old. Participants with missing information on any study variable or living in a single-parent household in 1983 were excluded. Single parent households were excluded to study the combined effect of both the mother and the father on their children. Full data were available for 1083 participants. 632 (58.4\%) of the participants were women and 451 (41.6\%) men.

\subsection{Measures}

2.2.1 Temperament and Character Inventory. We used version 9 of the TCI which has 240 items (Cloninger et al., 1994). Instead of the original true / false response format, we used a 5 point Likert-scale with response categories ranging from 1) absolutely false to 5) absolutely true. This response format increases the reliability of the results by making more fine-grained personality estimates possible (Goncalves and Cloninger, 2010).Temperament dimensions include Harm avoidance (HA; 35 items, Cronbach's $\alpha=0.92)$, Novelty seeking 
(NS; 40 items, $\alpha=0.85)$, Reward dependence (RD; 24 items, $\alpha=0.80)$ and Persistence (PS; 8 items, $\alpha=0.64)$. Character dimensions include Self-directedness (SD; 44 items, $\alpha=0.89$ ), Cooperativeness (CO; 42 items, $\alpha=0.91)$ and Self-transcendence (ST; 33 items, $\alpha=0.91)$. All temperament and character dimensions were standardized to have a mean of 0 and standard deviation of 1.

2.2.2 Hostile maternal care-giving environment. Maternal care-giving environment was self-rated by the mothers in 1983 . The scale consists of nine items measured on a 5-point scale. The items assess three dimensions: (a) the child's low emotional significance to the mother (e.g., "The child is significant to me," $1=$ very significant, $5=$ not significant, (b) the strict disciplinary style of the mother (e.g., "Disciplinary actions are regularly needed," $1=$ totally disagree, 5 = totally agree), and (c) the mother's low tolerance toward the child (e.g., "In difficult situations, the child is a burden," $1=$ totally disagree, $5=$ totally agree). The internal consistencies (Cronbach's alphas) for the individual dimensions have previously been shown to be acceptable, and for the entire Young Finns data are 0.77 for low emotional significance, 0.67 for strict discipline, and 0.71 for low tolerance (Räikkönen and Keltikangas-Järvinen, 1992). Internal consistencies for the sample in the present study are 0.75 for low emotional significance, 0.66 for strict discipline, and 0.70 for strict tolerance. Logarithmic transformation was applied to correct for the positive skewness, and the variable was standardized to have a mean of 0 and deviation of 1 .

2.2.3 Family's socioeconomic status. Family's socioeconomic status was assessed in year 1983 when the subjects were 6-21 years of age. As was done in two earlier Young Finns studies (Pulkki et al., 2003; Jokela et al., 2007), SES was measured by two indices: (a) the mother's and father's years of education (standardized z-score) and (b) the annual income of 
the household (measured on an eight-point scale standardized as a z-score). The Z scores of education and income were summed. The resulting index of parental socioeconomic status was standardized to have a mean of 0 and deviation of 1 .

2.2.4 Age of parents at the time of birth. Both the age of mother and father at the time of birth were used as predictors.

2.2.5 Parental unhealthy habits. Parental life habits were self-rated by the mothers and fathers in 1983. The scale consists of four items which are (1) alcohol use, (2) smoking, (3) body mass index and (4) free-time physical exercise. Alcohol use was measured by asking "how often do you use alcohol so that you become intoxicated?" It was rated on an eightpoint scale $(1=$ daily, $7=3-4$ times a year and $8=$ never $)$. Smoking was measured by asking "which of the following options describes best your current smoking habits?" It was rated with the following scale 1 = I smoke daily, 2 = I smoke occasionally, 3 = I do not smoke. Body mass index was calculated by dividing weight $(\mathrm{kg})$ by height $(\mathrm{m})$ squared. Weight and height were measured by a nurse. Free-time physical exercise was measured by asking "how often do you do physical exercise on your free-time?" It was rated on a six-point scale ( $1=$ daily, $5=$ once a month or less frequently, $6=\mathrm{I}$ do not do free-time physical exercise). Each of the four measures were re-coded as dichotomous $(0=$ healthy or $1=$ unhealthy). We used the following cutoff points. For alcohol use $8=$ never and $7=3-4$ times a year were coded as healthy. Options from $1=$ daily to $6=$ once in every two months were coded as unhealthy. For smoking, never smoking was coded as healthy and smoking occasionally or daily as unhealthy. For body mass index everyone above 25 (the World Health Organization's cutoff point for overweight) was coded as unhealthy and everyone below 25 as healthy. For free-time physical exercise (6) no free-time physical exercise was coded as 
unhealthy and all other options as healthy. These four recoded items were summed to form the parental unhealthy life style -variable (range from 0 to 4 ) separately for mothers and fathers.

2.2.6 Parental role dissatisfaction. Parental role dissatisfaction was self-rated by mothers and fathers in 1983. The scale consists of two items: dissatisfaction as a parent, and dissatisfaction as a spouse. Dissatisfaction as a parent was measured by asking: "evaluate yourself as a mother / father". A five-point scale was used $(1=$ satisfied, $5=$ not satisfied $)$. Dissatisfaction as a spouse was measured by asking: "evaluate yourself as spouse". A fivepoint scale was used $(1=$ satisfied, $5=$ not satisfied $)$. The variables were recoded as dichotomous variables $(0=$ satisfied or $1=$ unsatisfied $)$. The following cutoff points were used. For both dissatisfaction as a parent and dissatisfaction as a spouse, $1=$ satisfied and $2=$ rather satisfied were coded as satisfied. Options from $3=$ not satisfied not unsatisfied to $5=$ unsatisfied were coded as unsatisfied. The two recoded items were summed to form the parental dissatisfaction -variable separately for the mother and the father.

2.2.7 Cumulative risk-factor index. We followed the example of the most common way to form the cumulative risk index (Sabates and Dex, 2012) and formed our cumulative risk index as a combination of all the 8 paternal and / or maternal risk-factors (range between $0=$ no risk factors and $8=$ all eight parental risk factors). Presence of an individual risk factor was based on dichotomized variables (present vs. not present). Dichotomization for the continuous variables (age of parents at the time of birth, family SES, and hostile care-giving) was done by using median-split. Parental dissatisfaction was coded as 0 if no dissatisfaction was reported and 1 otherwise. Unhealthy habits were coded as 0 if there was at most one reported unhealthy habit and 1 otherwise. 


\subsection{Attrition analysis}

Full parental data from year 1983 were available for 1686 participants. Of these, 603 did not participate in year 2001. Men were more likely to non-participate than women in 2001 (43.8\% vs. $\left.28.5 \%, \chi^{2}(1)=42.6, \mathrm{P}<0.01\right)$. Mothers of the non-participants had higher level of hostile maternal care-giving $(\mathrm{t}(1684)=2.85$, Cohen's $\mathrm{d}=0.14)$, were more likely smokers $\left(42.8 \%\right.$ vs. $\left.34.0 \%, \chi^{2}(1)=9.0, P<0.01\right)$, used more likely unhealthy amounts of alcohol $\left(41.5 \%\right.$ vs. $\left.34.3 \%, \chi^{2}(1)=6.3, P=0.01\right)$, and were more dissatisfied as a mother $(41.9 \%$ vs. $\left.34.7 \%, \chi^{2}(1)=4.8, P=0.03\right)$. Fathers of the non-participants used more likely unhealthy amounts of alcohol $\left(38.7 \%\right.$ vs. $\left.32.8 \%, \chi^{2}(1)=6.5, \mathrm{P}=0.01\right)$.

\subsection{Statistical analyses}

We used linear regression analysis to explore the relationship between parental care-giving and family environment and the child's personality in adulthood. Sex and birth year of the child were controlled in all analyses. ANOVA was used to analyze the association between the cumulative risk index and the child's personality in adulthood. Analyses were conducted using PASW version 18.0.2.

\section{Results}

\subsection{Inter-correlations between parental care-giving and family environment}

Mother's and father's age $(r=0.78)$ at childbirth and dissatisfaction scores $(r=0.59)$ were strongly correlated. Other correlations were weaker; mother's and father's unhealthy habits correlated at 0.30 and hostile maternal care-giving and maternal dissatisfaction at 0.25. Family SES correlated only weakly with other variables (strongest correlation with father's unhealthy habits at -0.17 ). 


\subsection{Parental care-giving and family environment predicting offspring 's temperament}

Table 1 shows the relationship between parental care-giving and family environment and standardized temperament traits of offspring in adulthood after 18 years. None of the maternal variables predicted Novelty seeking. Father's unhealthy habits were associated with higher Novelty seeking. Higher maternal and paternal dissatisfaction predicted higher level of Harm avoidance. In addition, more hostile maternal care-giving and lower family SES were associated with higher Harm avoidance. Lower maternal dissatisfaction and higher family SES were associated with higher Reward dependence. Paternal variables were not significantly associated with Reward dependence. High Persistence was predicted by high family SES but not by any other parental variables. All maternal variables together explained at most $1.4 \%$ (Reward dependence) and paternal variables $0.7 \%$ (Harm avoidance) of the variance in the temperament traits.

\subsection{Parental care-giving and family environment predicting offspring's character}

Table 2 shows the relationship between parental care-giving and family environment and offspring's standardized character traits in adulthood after 18 years. All variables except father's age at childbirth were associated with Self-directedness. Higher hostile maternal care-giving, higher number of parents' unhealthy habits, and higher dissatisfaction were associated with lower Self-directedness. Higher family SES and higher mother's age at childbirth were associated with higher Self-directedness. All variables except father's age at childbirth and family SES were associated with Cooperativeness. Higher hostile maternal care-giving, higher number of parents' unhealthy habits, and higher dissatisfaction were associated with lower Cooperativeness. Higher mother's age at childbirth was associated with higher Cooperativeness. Self-transcendence was not predicted by any of the parental 
variables. All maternal variables together explained at most 5.2\% (Self-directedness) and paternal variables $2.4 \%$ (Self-directedness) of the variance in the character traits.

\subsection{Cumulative risk-factor index and the child's personality}

Figures 1 and 2 show the relationship between the number of parental risk-factors (cumulative risk-factor index) and the child's subsequent standardized personality traits. Novelty Seeking ranged from -0.31 to 0.14 , Harm Avoidance from -0.33 to 0.25 , Reward Dependence from -0.75 to 0.10 , Persistence from -0.27 to 0.25 , Self-directedness from -0.49 to 0.62 , Cooperativeness from -0.75 to 0.66 , and Self-transcendence from -0.19 to 0.18 . The levels of Novelty seeking, Persistence, and Self-transcendece were not associated with the number of risk factors. There were differences in Harm avoidance $(\mathrm{p}=0.05)$, Reward dependence $(\mathrm{p}<0.01)$, Self-directedness $(\mathrm{p}<0.01)$, and Cooperativeness $(\mathrm{p}<0.01)$ according to the level of risk factors. Linear contrast showed that these associations followed a linear trend so that the level of Harm avoidance $(\mathrm{p}=0.02)$ increased and the level of Reward dependence $(\mathrm{p}<0.01)$, Self-directedness $(\mathrm{p}<0.01)$, and Cooperativeness $(\mathrm{p}<0.01)$ decreased along with increasing cumulative childhood burden. According to regression coefficients, cumulative risk was more strongly associated with character $(B=-0.12$ for Selfdirectedness and $\mathrm{B}=-0.10$ for Cooperativeness) than with temperament $(\mathrm{B}=0.06$ for Harm avoidance and $\mathrm{B}=-0.06$ for Reward dependence).

\section{Discussion}

Our results show that different domains of adult personality are differently related to childhood measures of parental behaviors and family environment. Compared to the four temperament traits of the TCI, character traits of offspring, Self-directedness and Cooperativeness in particular, were more strongly predicted by measures of parental behavior 
and childhood environment. This finding is in agreement with our hypothesis suggesting that temperament traits, which are postulated to measure automatic reactions to stimuli, are less malleable by childhood experiences than character traits, which are suggested to measure sociocultural learning and psychological maturity. The difference was observed with both maternal and paternal variables. Furthermore, in agreement with the cumulative stressors model, the number of childhood risk factors was strongly and linearly associated with the character traits of Self-directedness and Cooperativeness. The association between the number of childhood risk factors and the temperament traits of Harm avoidance and Reward dependence was weaker and not as clearly linear as for the character traits.

\subsection{Strengths and limitations}

The present results indicate that family environment predicts character development. However, causal inferences concerning the mediating mechanisms cannot be established based on the present observations. Intergenerational genetic transmission may account for some of our observations, that is, parental behaviors may correlate with offspring personality due to a shared genetic background. Although genetic component has been shown to be equally strong for temperament and character traits (Gillespie et al., 2003), we found that not all personality traits are similarly predicted by parental care-giving and family environment. Character development was more strongly related to such measures than temperament, and a strong linear association between cumulative risk score and personality was observed only for Self-Directedness and Cooperativeness but not for other traits. This suggests that shared genetic background is unlikely to explain the present patterns completely, because character traits are no less heritable than temperament traits but they still show different associations with childhood measures. It is also possible that the associations we found might in part reflect a reverse direction of causality; it might be that the characteristics of the child are 
causing the observed behavior in the parent (Jokela, 2010). This is possible especially for hostile maternal child-rearing practice and parental dissatisfaction.

Paternal care-giving environment was not measured directly in the present study. This is a limitation although mothers are usually children's primary caregivers and, thus, are likely to have a larger impact on the total care-giving environment than fathers.

Attrition analysis indicated that the non-participants in year 2001 had more dissatisfied mothers who smoked and drank more and fathers who drank more than the parents of the willing participants in year 2001. In short, the non-participants had more parental risk factors than the participants. We showed that participants with more parental risk factors had lower Cooperativeness and lower Self-directedness which are associated with ill-being and psychopathology. This implies that the non-participants are likely to be those who have been most negatively affected by risky care-giving and family-environment. This is likely to restrict the range of variance in the outcome variable, thereby lowering the effect size of the family environment in the present study.

Although the study was prospective, the age range of the participants was fifteen years. Therefore, the youngest children were six years old and the oldest 21 at the time the parents self-assessed themselves. This might have affected the results although child's birth year was statistically controlled. However, family environment tends to remain rather stable with time so family environment at one point in time is a reasonable approximation of the family environment in the past or in the future (Repetti et al., 2011). It is, nonetheless, possible that a parent practices healthy habits when the child is older but practiced unhealthy habits (e.g., drank more) when the child was younger. Parent's behavior when the child is older is probably not as important for personality development as when the child is younger which might weaken the associations between family environment and personality in the present study. 
Our study had also notable strengths compared to most previous research on the subject. First, our study was based on a non-clinical population based sample, which made it possible to study the effects of non-pathological variation in family environment on children. Second, the present study was prospective with a long time-span of 18 years. Third, the same informant did not provide data for both the parental variables and the adulthood personality; the parents assessed themselves, and the children self-rated their own personality 18 years later. Fourth, the parental variables we measured (care-giving, SES, age, unhealthy habits, and dissatisfaction) capture rather well the wide family context factors that can influence child development (Sheffield Morris et al., 2007). Fifth, we measured personality with a wellknown and comprehensive personality inventory (TCI), which separates temperament from character; this made it possible to study separately the effects of childhood environment on traits reflecting basic behavioral responses (temperament) and on traits related to higher cognitive functions (character).

\subsection{Mechanisms that explain the specific associations}

The association between parental care-giving and family-environment and the offspring's Self-directedness and Cooperativeness is in line with previous findings showing that parental acceptance and responsiveness predict positive child development outcomes such as selfregulation, sociability and self-esteem (Cummings et al., 2003), all of which are essential components of a mature personality. Hostile childrearing and parental dissatisfaction in marital and parental roles predicted higher Harm avoidance and lower Self-directedness and Cooperativeness. People with high Harm avoidance and low Self-directedness are more likely to have different kinds of psychopathology in adulthood (Cloninger et al., 2010). Marriage can be a source of stress or support for the parenting role (Grych, 2002). A bad marriage can sap energy, attention and resources from the parents after which they cannot focus on their 
children's needs. Family conflict and hostile rearing may impair children's social competence (Cooperativeness) and emotion regulation skills (Self-directedness) (Repetti et al., 2002; Pomerantz and Thompson, 2008). Social interaction with parents shapes children's understanding of, expectations about and behavior in relationships with other people (McHale et al., 2003).

Low socioeconomic status (SES) of the family may also have adverse effects on the functioning of the family (Bornstein, 2006). Low-SES families have less and lower quality resources available (e.g., money and social capital) which may cause stress in family members and, consequently, cause parents to be more hostile towards their children and their partners (Repetti et al., 2002; Hearn, 2011). Low SES can cause poor developmental outcomes through at least five different pathways: a) health and nutrition, b) home environment, c) parental interactions with a child, d) parental mental health, and e) neighborhood conditions (BrooksGunn and Duncan, 1997).

Our results show that children of younger mothers grow up to be slightly less selfdirected and cooperative than others. However, the effect of age in our sample was not very strong. Previous evidence shows that parents' age might affect the way children are raised and treated. Young parental age, in general, is associated with increased levels of child's psychopathology and behavioral problems, and with less available parental resources (Orlebeke et al., 1998; Fergusson and Woodward, 1999; Powell et al., 2006).

\subsection{The developmental path from childhood to adulthood}

Our results demonstrate that the associations between parental care-giving and family environment and children's personality persist over eighteen years even when the measured parental variables include "normal variation" in parental behavior rather than severe child maltreatment. Together with the fact that character traits are most affected by environmental 
exposures this has important implications for the understanding of normal and abnormal development. Immature character (low Self-directedness and low Cooperativeness) predisposes a person to personality disorders and psychopathology in general (Cloninger et al., 2010; Josefsson et al., 2011). Personality disorders have been suggested to derive from extreme levels of normal personality traits (Paris, 1998; Shiner, 2009). Previous research has shown that childhood experiences are important to the development of personality disorders as well as mood disorders (Battle et al., 2004; Tyrka et al., 2009; Kessler et al., 2010). It is possible that low Cooperativeness and low Self-directedness mediate the associations between risky childhood environments and adulthood mental health outcomes. We also found that maternal care-giving and family environment have a greater effect on child's personality than paternal variables which is line with previous research (Reti et al., 2002). This can probably be explained by the fact that mothers are usually children's primary caregivers (Schumacher et al., 2001).

There can be both risky and protective factors and processes present in children's lives. The balance between these factors determines whether the outcome of child development will be positive or negative (Cicchetti, 2004; Cicchetti and Toth, 2005; Dubowitz and Bennett, 2007). Childhood environment is important but it interacts with several other factors defining the adulthood personality. This is probably why the parental care-giving and family-environment in our study did not explain more than $5 \%$ of the variation in any of the personality traits. Negative events and circumstances in childhood contribute to maladaptive personality but they are not defining causes; many children with negative experiences grow up to be well-functioning (Paris, 1998; Cicchetti and Toth, 2005). Some childhood adversity effects may depend on later stressors while others might be confined to individuals with pre-existing vulnerabilities (Maughan and McCarthy, 1997). All the links in the developmental chain are important and not just the first and the last (Schaffer, 
2000). The outcome depends for the most part on the cumulative effect of circumstances and experiences before and after a single negative incident (Sroufe et al., 2010).

\subsection{Cumulative environmental stressors}

Previous studies on cumulative stressors have shown higher cumulative risk in childhood to be associated with lower intelligence, lower resiliency and even increased mortality risk (Sameroff et al., 1987; Jaffee et al., 2007; Jokela et al., 2009). In the present study, accumulation of several childhood risk factors was linearly associated with the most immature personality (low Self-directedness and low Cooperativeness) whereas no clear dose-response association was observed for Self-transcendence or any of the temperament traits. The results imply that single measures of parental care-giving and family environment may not be sufficient in measuring the relevant childhood exposures that are relevant for later character development. Rather, early developmental environment may be best conceptualized as a multidimensional clustering of risk factors that are predictive of personality development in concert with each other.

Personality development depends partly on the experiences made available to the child (Cicchetti and Toth, 2005). This emphasizes the need of an early intervention for badly functioning families, and, at the same time, raises hopes that a well-planned intervention can support character development. Most importantly, not all personality traits are affected equally by the family environment. Our findings suggest that maturity-related aspects of personality seem to be more strongly influenced by childhood exposures than temperament which, by definition, has a strong inherited component. This should be taken into account when planning an intervention and directing the available resources. Interventions directed at childhood factors, such as those assessed in the current study, are more likely to have an effect on character development than on temperament development. The results suggest that 
interventions should not concentrate on the quality or intensity of emotions children feel but to living a balanced life with awareness and understanding of one's emotions.

Our results on the number of childhood risk factors are in line with previous findings showing that it is probable that focusing on one childhood adversity among individuals exposed to many will not have important positive effects (Kessler et al., 2010). A successful intervention should target all dysfunctional aspects of a child's life at the same time since they all interact (Cicchetti, 2004). This goal, however, is complicated by the fact that there are no typical risk factor clusters or typical risk families (Sabates and Dex, 2012). This means that it is hard or even impossible to develop a general policy for interventions (Sabates and Dex, 2012).

\subsection{Conclusion}

We have shown that parental care-giving and family environment predict child's personality over 18 years. Compared to behavioral-emotional aspects of personality measured by temperament traits, the development of mature adult personality was more strongly related to childhood parental behaviors and family-environment. This was most clearly illustrated by the cumulative stressor model, which demonstrated a clear linear association between cumulative childhood risk score and Self-Directedness and Cooperativeness but not with other traits. Thus, a sub-optimal childhood developmental environment appears to hamper specific aspects of personality development related to maturity. In agreement with our previous study of developmental trajectories of personality (Josefsson et al., 2012), the present results demonstrate developmental differences between temperament versus character traits. We raise a possibility that immature personality development may explain why childhood neglect leads to a high risk for adulthood psychopathology. This question will be a topic of future studies. 


\section{Acknowledgements}

This study was supported by Emil Aaltonen Foundation (MH), Niilo Helander Foundation $(\mathrm{MH})$, Ella and Georg Ehrnrooth Foundation $(\mathrm{MH})$, the University of Helsinki Research Funds (MH), the Academy of Finland (grant 123621 to LP-R), Alfred Kordelin Foundation (PM), Finnish Cultural Foundation (PM)

Figure Captions

Figure 1. Standardized scores (mean $=0, \mathrm{SD}=1)$ of the child's temperament traits in 2001 grouped by the number of parental risk factors in 1983. Sex and birth year were controlled. Results of ANOVA: NS $(\mathrm{F}(8,1068)=1.47, P=0.16), \mathrm{HA}(\mathrm{F}(8,1068)=1.98, P=0.05), \mathrm{RD}$ $(\mathrm{F}(8,1068)=2.79, P<0.01), \mathrm{PS}(\mathrm{F}(8,1068)=1.53, P=0.14)$. Linear contrasts: $\mathrm{NS}(P=$ $0.73)$, HA $(P=0.02), \mathrm{RD}(P<0.01)$, PS $(P=0.47)$. Regression coefficients (number of parental risk factors as the independent variable): $\mathrm{NS}(\mathrm{B}=0.03, P=0.07), \mathrm{HA}(\mathrm{B}=0.06, P<$ $0.01), \mathrm{RD}(\mathrm{B}=-0.06, P<0.01), \mathrm{P}(\mathrm{B}=0.02, P=0.38)$.

Figure 2. Standardized scores (mean $=0, \mathrm{SD}=1)$ of the child's character traits in 2001 grouped by the number of parental risk factors in 1983. Sex and birth year were controlled. Results of ANOVA: $\mathrm{SD}(\mathrm{F}(8,1068)=5.79, P<0.01), \mathrm{CO}(\mathrm{F}(8,1068)=5.06, P<0.01), \mathrm{ST}$ $(\mathrm{F}(8,1068)=1.06, P=0.39)$. Linear contrasts: SD $(P<0.01), \mathrm{CO}(P<0.01), \mathrm{ST}(P=0.63)$. Regression coefficients (number of parental risk factors as the independent variable): SD (B $=-0.12, P<0.01), \mathrm{CO}(\mathrm{B}=-0.10, P<0.01), \mathrm{ST}(\mathrm{B}=0.00, P=0.90)$. 


\section{References}

Ainsworth, M., Blehar, M., Waters, E., Wall, S., 1978. Patterns of Attachment. Erlbaum, Hillsdale, NJ.

Anisman, H., Zaharia, M.D., Meaney, M.J., Merali, Z., 1998. Do early-life events permanently alter behavioral and hormonal responses to stressors? International Journal of Developmental Neuroscience 16, 149-164.

Atzaba-Poria, N., Pike, A., Deater-Deckard, K., 2004. Do risk factors for problem behaviour act in a cumulative manner? An examination of ethnic minority and majority children through an ecological perspective. Journal of Child Psychology and Psychiatry 45, 707-718.

Bakermans-Kranenburg, M.J., van IJzendoorn, M.H., Bokhorst, C.L., Schuengel, C., 2004. The importance of shared environment in infant-father attachment: A behavioral genetic study of the Attachment Q-Sort. Journal of Family Psychology 18, 545-549.

Battle, C.L., Shea, M.T., Johnson, D.M., Yen, S., Zlotnick, C., Zanarini, M.C., Sanislow, C.A., Skodol, A.E., Gunderson, J.G., Grilo, C.M., McGlashan, T.H., Morey, L.C., 2004. Childhood maltreatment associated with adult personality disorders: Findings from the collaborative longitudinal personality disorders study. Journal of Personalilty Disorders 18, 193-211.

Baumrind, D., 1967. Child Care Practices Anteceding 3 Patterns of Preschool Behavior. Genetic Psychology Monographs 75, 43-88. 
Bokhorst, C., Bakermans-Kranenburg, M., Fearon, R., van IJzendoorn, M., Fonagy, P., Schuengel, C., 2003. The importance of shared environment in mother-infant attachment security: A behavioral genetic study. Child Development 74, 1769-1782.

Bornstein, M.H., 2006. Parenting science and practice, in Damon, W., Lerner, R.M. (Eds.), Handbook of Child Psychology: Vol. 4. Child Psychology in Practice, 6th ed. John Wiley \& Sons, New Jersey, pp. 893-949.

Bowlby, J., 1969. Attachment and Loss: Vol. 1. Attachment. Basic Books, New York.

Brewin, C.R., Andrews, B., Gotlib, I.H., 1993. Psychopathology and Early Experience - a Reappraisal of Retrospective Reports. Psychological Bulletin 113, 82-98.

BrooksGunn, J., Duncan, G.J., 1997. The effects of poverty on children. Future of Children 7, $55-71$.

Caspi, A., Moffitt, T.E., Morgan, J., Rutter, M., Taylor, A., Arseneault, L., Tully, L., Jacobs, C., Kim-Cohen, J., Polo-Tomas, M., 2004. Maternal expressed emotion predicts children's antisocial behavior problems: Using monozygotic-twin differences to identify environmental effects on behavioral development. Developmental Psychology 40, 149-161.

Cicchetti, D., 2004. An odyssey of discovery: Lessons learned through three decades of research on child maltreatment. American Psychologist 59, 731-741.

Cicchetti, D., Toth, S.L., 2005. Child maltreatment. Annual Review of Clinical Psychology 1, 409-438.

Cloninger, C.R., 1994a. Temperament and personality. Current Opinion in Neurobiology 4, 266-273. 
Cloninger, C.R., 1994b. The genetic structure of personality and learning: a phylogenetic model, Clinical Genetics 46, 124-137.

Cloninger, C.R., 2008. The psychobiological theory of temperament and character: Comment on Farmer and Goldberg (2008). Psychological Assessment 20, 292-299.

Cloninger, C.R., Przybeck, T.R., Svrakic, D.M., Wetzel, R.D., 1994. The Temperament and Character Inventory (TCI): A Guide to its Development and use. Washington University Center for Psychobiology of Personality, St Louis.

Cloninger, C.R., Svrakic, D.M., Przybeck, T.R., 1993. A Psychobiological Model of Temperament and Character. Archives of General Psychiatry 50, 975-990.

Cloninger, C.R., Svrakic, N.M., Svrakic, D.M., 1997. Role of personality self-organization in development of mental order and disorder. Development and Psychopathology. 9, 881-906.

Cloninger, C.R., Zohar, A.H., Cloninger, K.M., 2010. Promotion of well-being in personcentered mental health care. Focus 8, 165-179.

Collins, W.A., Maccoby, E.E., Steinberg, L., Hetherington, E.M., Bornstein, M.H., 2000. Contemporary research on parenting - The case for nature and nurture. American Psychologist 55, 218-232.

Cummings, E.M., Braungart-Rieker, J.M., Rocher-Schudlich, T.D., 2003. Emotion and personality development in childhood, in Weiner, I.B. (Ed.), Handbook of Psychology: Vol. 6. Developmental Psychology. John Wiley \& Sons, New Jersey, pp. 211-239. 
Dubowitz, H., Newton, R.R., Litrownik, A.J., Lewis, T., Briggs, E.C., Thompson, R., English, D., Lee, L.C., Feerick, M.M., 2005. Examination of a conceptual model of child neglect. Child Maltreat. 10, 173-189.

Dubowitz, H., Bennett, S., 2007. Physical abuse and neglect of children. Lancet 369, 18911899.

Evans, G.W., 2003. A multimethodological analysis of cumulative risk and allostatic load among rural children. Developmental Psychology 39, 924-933.

Fergusson, D., Woodward, L., 1999. Maternal age and educational and psychosocial outcomes in early adulthood. Journal of Child Psychology and Psychiatry 40, 479-489.

Flouri, E., 2008. Contextual risk and child psychopathology. Child Abuse and Neglect 32, 913-917.

Gillespie, N.A., Cloninger, C.R., Heath, A.C., Martin, N.G., 2003. The genetic and environmental relationship between Cloninger's dimensions of temperament and character. Personality and Individual Differences 35, 1931-1946.

Goncalves, D.M., Cloninger, C.R., 2010. Validation and normative studies of the Brazilian Portuguese and American versions of the Temperament and Character Inventory — Revised (TCI-R). Journal of Affective Disorders 124, 126-133.

Grych, J.H., 2002. Marital relationships and parenting, in Bornstein, M.H. (Ed.), Handbook of Parenting: Vol 4. Social Conditions and Applied Parenting, 2nd ed. Lawrence Erlbaum Associates, New Jersey, pp. 203-225. 
Harris, J.R., 1995. Where is the child's environment? A group socialization theory of development. Psychological Review 102, 458-489.

Hearn, J., 2011. Unmet needs in addressing child neglect: Should we go back to the drawing board? Children and Youth Services Review 33, 715-722.

Hildyard, K.L., Wolfe, D.A., 2002. Child neglect: developmental issues and outcomes. Child Abuse and Neglect 26, 679-695.

Hojat, M., Borenstein, B.D., 1990. Perception of childhood dissatisfaction with parents and selected personality traits in adulthood. Journal of General Psychology 117, 241.

Jaffee, S.R., Caspi, A., Moffitt, T.E., Polo-Tomas, M., Taylor, A., 2007. Individual, family, and neighborhood factors distinguish resilient from non-resilient maltreated children: A cumulative stressors model. Child Abuse and Neglect. 31, 231-253.

Jokela, M., 2010. Characteristics of the First Child Predict the Parents' Probability of Having Another Child. Developmental Psychology 46, 915-926.

Jokela, M., Ferrie, J., Kivimaki, M., 2009. Childhood Problem Behaviors and Death by Midlife: The British National Child Development Study. Journal of the American Academy of Child and Adolescent Psychiatry 48, 19-24.

Jokela, M., Lehtimaki, T., Keltikangas-Jarvinen, L., 2007. The serotonin receptor 2A gene moderates the influence of parental socioeconomic status on adulthood harm avoidance. Behavioral Genetics 37, 567-574. 
Josefsson, K., Cloninger, C.R., Hintsanen, M., Jokela, M., Pulkki-Råback, L., KeltikangasJärvinen, L., 2011. Associations of personality profiles with various aspects of well-being: A population-based study. Journal of Affective Disorders 133, 265-273.

Josefsson, K., Jokela, M., Cloninger, C.R., Hintsanen, M., Salo, J., Hintsa, T., PulkkiRåback, L., Keltikangas-Järvinen, L., 2012. Maturity and change in personality: Developmental trends of temperament and character in adulthood. Development and Psychopathology (in press) .

Josefsson, K., Merjonen, P., Jokela, M., Pulkki-Råback, L., Keltikangas-Järvinen, L., 2011. Personality profiles identify depressive symptoms over te nyears? A population-based study. Depression Research and Treatment 2011, 1-11.

Keller, H., Lamm, B., Abels, M., Yovsi, R., Borke, J., Jensen, H., Papaligoura, Z., Holub, C., Lo, W., Tomiyama, A.J., Su, Y., Wang, Y., Chaudhary, N., 2006. Cultural Models, Socialization Goals, and Parenting Ethnotheories. Journal of Cross-Cultural Psychology 37, $155-172$.

Kessler, R.C., McLaughlin, K.A., Green, J.G., Gruber, M.J., Sampson, N.A., Zaslavsky, A.M., Aguilar-Gaxiola, S., Alhamzawi, A.O., Alonso, J., Angermeyer, M., Benjet, C., Bromet, E., Chatterji, S., de Girolamo, G., Demyttenaere, K., Fayyad, J., Florescu, S., Gal, G., Gureje, O., Maria Haro, J., Hu, C., Karam, E.G., Kawakami, N., Lee, S., Lepine, J., Ormel, J., Posada-Villa, J., Sagar, R., Tsang, A., Uestuen, T.B., Vassilev, S., Viana, M.C., Williams, D.R., 2010. Childhood adversities and adult psychopathology in the WHO World Mental Health Surveys. British Journal of Psychiatry 197, 378-385. 
Lundberg, M., Perris, G., Schlette, P., Adolfsson, R., 1999. Transhistorical variations in personality and their association with experiences of parental rearing. European Psychiatry 14, 303-318.

Maccoby, E.E., 2000. Parenting and its effects on children: On reading and misreading behavior genetics. Annual Review of Psychology 51, 1-27.

Maughan, B., McCarthy, G., 1997. Childhood adversities and psychosocial disorders.British Medical Bulletin 53, 156-169.

Mccrae, R.R., Costa, P.T., 1988. Recalled Parent-Child Relations and Adult Personality. Journal of Personality 56, 417-434.

McHale, S.M., Dariotis, J.K., Kauh, T.J., 2003. Social development and social relationships in middle childhood, in Weiner, I.B. (Ed.), Handbook of Psychology: Vol. 6. Developmental Psychology. John Wiley \& Sons, New Jersey, pp. 241-265.

Meaney, M., 2001. Maternal care, gene expression, and the transmission of individual differences in stress reactivity across generations. Annual Review of Neuroscience 24, 11611192.

Mersky, J.P., Topitzes, J., 2010. Comparing early adult outcomes of maltreated and nonmaltreated children: A prospective longitudinal investigation. Children and Youth Services Review 32, 1086-1096.

Nakao, K., Takaishi, J., Tatsuta, K., Katayama, H., Iwase, M., Yorifuji, K., Takeda, M., 2000. The influences of family environment on personality traits. Psychiatry and Clinical Neurosciences 54, 91-95. 
Orlebeke, J., Knol, D., Boomsma, D., Verhulst, F., 1998. Frequency of parental report of problem behavior in children decreases with increasing maternal age at delivery. Psychological Reports 82, 395-404.

Oshino, S., Suzuki, A., Ishii, G., Otani, K., 2007. Influences of parental rearing on the personality traits of healthy Japanese. Comprehensive Psychiatry 48, 465-469.

Paris, J., 1998. Does childhood trauma cause personality disorders in adults? Canadian Journal of Psychiatry 43, 148-153.

Pomerantz, E.M., Thompson, R.A., 2008. Parents' role in children's personality development: The psychological resource principle, in John, O.P., Robins, R.W., Pervin, L.A. (Eds.), Handbook of Personality: Theory and Research, 3rd ed. The Guilford Press, New York, pp. 351-374.

Powell, B., Steelman, L., Carini, R., 2006. Advancing age, advantaged youth: Parental age and the transmission of resources to children. Social Forces 84, 1359-1390.

Pulkki, L., Keltikangas-Jarvinen, L., Ravaja, N., Viikari, J., 2003. Child-rearing attitudes and cardiovascular risk among children: Moderating influence of parental socioeconomic status. Preventive Medicine 36, 55-63.

Räikkönen, K., Keltikangas-Järvinen, L., 1992. Childhood Hyperactivity and the MotherChild-Relationship as Predictors of Risk Type-A Behavior in Adolescence - a 6-Year FollowUp. Personality and Individual Differences 13, 321-327.

Raitakari, O.T., Juonala, M., Ronnemaa, T., Keltikangas-Jarvinen, L., Rasanen, L., Pietikainen, M., Hutri-Kahonen, N., Taittonen, L., Jokinen, E., Marniemi, J., Jula, A., Telama, R., Kahonen, M., Lehtimaki, T., Akerblom, H.K., Viikari, J.S.A., 2008. Cohort 
Profile: The Cardiovascular Risk in Young Finns Study. International Journal of Epidemiology 37, 1220-1226.

Repetti, R.L., Taylor, S.E., Seeman, T.E., 2002. Risky Families: Family Social Environments and the Mental and Physical Health of Offspring. Psychological Bulletin 128, 330-366.

Repetti, R.L., Robles, T.F., Reynolds, B., 2011. Allostatic processes in the family. Development and Psychopathology 23, 921-938.

Reti, I.M., Samuels, J.F., Eaton, W.W., Bienvenu, O.J., Costa, P.T., Nestadt, G., 2002. Influences of parenting on normal personality traits. Psychiatry Research 111, 55-64.

Roisman, G.I., Fraley, R.C., 2006. The limits of genetic influence: A behavior-genetic analysis of infant-caregiver relationship quality and temperament. Child Development 77, $1656-1667$.

Sabates, R., Dex, S., 2012. Multiple risk factors in young children's development. Centre for Longitudinal Studies, London, CLS Cohort Studies 1.

Sameroff, A., Seifer, R., Barocas, R., Zax, M., Greenspan, S., 1987. Intelligence Quotient Scores of 4-Year-Old Children - Social-Environmental Risk-Factors. Pediatrics 79, 343-350.

Scarr, S., 1992. Developmental Theories for the 1990s - Development and IndividualDifferences. Child Development 63, 1-19.

Schaffer, H.R., 2000. The early experience assumption: Past, present, and future. International Journal of Behavioral Development 24, 5-14.

Schilling, E.A., Aseltine, R.H., Jr., Gore, S., 2007. Adverse childhood experiences and mental health in young adults: a longitudinal survey. BMC Public Health 7, 30. 
Schlette, P., Brändström, S., Eisemann, M., Sigvardsson, S., Nylander, P., Adolfsson, R., Perris, C., 1998. Perceived parental rearing behaviours and temperament and character in healthy adults. Personality and Individual Differences 24, 661-668.

Schumacher, J.A., Slep, A.M.S., Heyman, R.E., 2001. Risk factors for child neglect. Aggression and Violent Behavior 6, 231-254.

Scott, K.M., Smith, D.R., Ellis, P.M., 2010. Prospectively Ascertained Child Maltreatment and Its Association With DSM-IV Mental Disorders in Young Adults. Archives of General Psychiatry 67, 712-719.

Sheffield Morris, A., Silk, J.S., Steinberg, L., Myers, S.S., Robinson, L.R., 2007. The role of the family context in the development of emotion regulation. Social Development 16, 361388.

Shiner, R.L., 2009. The development of personality disorders: Perspectives from normal personality development in childhood and adolescence. Development and Psychopathology $21,715-734$.

Sroufe, L.A., Coffino, B., Carlson, E.A., 2010. Conceptualizing the role of early experience: Lessons from the Minnesota longitudinal study. Developmental Review 30, 36-51.

Takeuchi, M.S., Miyaoka, H., Suzuki, M., Tomoda, A., Yokoo, A.I., Tsutsumida, R., Kitamura, T., 2011. The relationship of temperament and character dimensions to perceived parenting styles in childhood: A study of a Japanese university student population. The Open Family Studies Journal 4, 9-14.

Taylor, S.E., Way, B.M., Seeman, T.E., 2011. Early adversity and adult health outcomes. Development and Psychopathology 23, 939-954. 
Tulviste, T., Mizera, L., De Geer, B., Tryggvason, M., 2007. Child-rearing goals of estonian, finnish, and swedish mothers. Scandinavian Journal of Psychology 48, 487-497.

Tyrka, A.R., Wyche, M.C., Kelly, M.M., Price, L.H., Carpenter, L.L., 2009. Childhood maltreatment and adult personality disorder symptoms: Influence of maltreatment type. Psychiatry Research 165, 281-287.

Zhang, T., Meaney, M.J., 2010. Epigenetics and the Environmental Regulation of the Genome and Its Function. Annual Review of Psychology 61, 439-466. 
Table 1

Regression coefficients of care-giving and home-environment predicting offspring's standardized temperament traits in adulthood

\begin{tabular}{|c|c|c|c|c|c|c|c|c|c|c|c|c|c|c|c|c|}
\hline & \multicolumn{4}{|c|}{ Novelty seeking } & \multicolumn{4}{|c|}{ Harm avoidance } & \multicolumn{4}{|c|}{ Reward dependence } & \multicolumn{4}{|l|}{ Persistence } \\
\hline & $\mathrm{B}(\mathrm{SE})$ & $\mathrm{P}$ & $\Delta \mathrm{R}^{2}$ & $\mathrm{R}^{2}$ & $\mathrm{~B}(\mathrm{SE})$ & $\mathrm{P}$ & $\Delta \mathrm{R}^{2}$ & $\mathrm{R}^{2}$ & $\mathrm{~B}(\mathrm{SE})$ & $\mathrm{P}$ & $\Delta \mathrm{R}^{2}$ & $\mathrm{R}^{2}$ & $\mathrm{~B}(\mathrm{SE})$ & $\mathrm{P}$ & $\Delta \mathrm{R}^{2}$ & $\mathrm{R}^{2}$ \\
\hline Mother & & & $0.4^{\mathrm{a}}$ & 1.2 & & & $1.3^{\mathrm{a}}$ & 4.5 & & & $1.4^{\mathrm{a}}$ & 15.2 & & & $0.3^{\mathrm{a}}$ & 1.1 \\
\hline Hostile rearing & $0.06(0.03)$ & 0.07 & 0.2 & 1.0 & $0.07(0.03)$ & 0.02 & 0.4 & 3.6 & $-0.05(0.03)$ & 0.11 & 0.1 & 13.9 & $0.02(0.03)$ & 0.50 & $<0.1$ & 0.7 \\
\hline Unhealthy habits & $0.05(0.03)$ & 0.17 & $<0.1$ & 0.8 & $0.05(0.03)$ & 0.12 & 0.1 & 3.3 & $-0.02(0.03)$ & 0.54 & $<0.1$ & 13.8 & $0.06(0.03)$ & 0.09 & 0.1 & 0.9 \\
\hline Dissatisfaction & $0.01(0.05)$ & 0.88 & $<0.1$ & 0.7 & $0.16(0.05)$ & $<0.01$ & 0.9 & 4.1 & $-0.15(0.04)$ & $<0.01$ & 0.9 & 14.7 & $0.00(0.05)$ & 0.99 & $<0.1$ & 0.7 \\
\hline Family SES & $0.05(0.03)$ & 0.11 & 0.1 & 0.9 & $-0.06(0.03)$ & 0.03 & 0.3 & 3.5 & $0.08(0.03)$ & 0.01 & 0.5 & 14.3 & $0.06(0.03)$ & 0.03 & 0.3 & 1.1 \\
\hline Age at childbirth & $-0.01(0.01)$ & 0.17 & $<0.1$ & 0.8 & $0.00(0.01)$ & 0.92 & $<0.1$ & 3.1 & $0.01(0.01)$ & 0.09 & 0.1 & 13.9 & $0.00(0.01)$ & 0.77 & $<0.1$ & 0.7 \\
\hline Father & & & $0.6^{\mathrm{b}}$ & 1.4 & & & $0.7^{\mathrm{b}}$ & 3.9 & & & $0.6^{\mathrm{b}}$ & 14.4 & & & $0.1^{\mathrm{b}}$ & 0.9 \\
\hline Unhealthy habits & $0.07(0.03)$ & 0.02 & 0.4 & 1.2 & $0.04(0.03)$ & 0.20 & $<0.1$ & 3.2 & $-0.03(0.03)$ & 0.29 & $<0.1$ & 13.8 & $-0.01(0.03)$ & 0.71 & $<0.1$ & 0.7 \\
\hline Dissatisfaction & $0.05(0.04)$ & 0.26 & $<0.1$ & 0.8 & $0.10(0.04)$ & 0.02 & 0.4 & 3.6 & $-0.07(0.04)$ & 0.07 & 0.2 & 14.0 & $-0.01(0.04)$ & 0.82 & $<0.1$ & 0.7 \\
\hline Age at childbirth & $-0.01(0.01)$ & 0.12 & 0.1 & 0.9 & $0.00(0.01)$ & 0.51 & $<0.1$ & 3.1 & $0.00(0.01)$ & 0.75 & $<0.1$ & 13.7 & $-0.01(0.01)$ & 0.26 & $<0.1$ & 0.8 \\
\hline
\end{tabular}

Note. $\mathrm{R}^{2}=$ adjusted $\mathrm{R}^{2}, \Delta \mathrm{R}^{2}=$ change in adjusted $\mathrm{R}^{2}$ compared to the model with only sex and birth year

B coefficients are reported for separate regression models, adjusted for sex and birth year

Mother and father share the same family SES 
${ }^{\text {a }} \mathrm{R}^{2}$ and change in $\mathrm{R}^{2}$ compared to the model with only sex and birth year: all maternal characteristics and family SES in the same multiple regression model

${ }^{b} R^{2}$ and change in $R^{2}$ compared to the model with only sex and birth year: all paternal characteristics and family SES in the same multiple regression model 
Table 2

Regression coefficients of care-giving and home-environment predicting offspring's standardized character traits in adulthood

\begin{tabular}{|c|c|c|c|c|c|c|c|c|c|c|c|c|}
\hline & \multicolumn{4}{|c|}{ Self-directedness } & \multicolumn{4}{|c|}{ Cooperativeness } & \multicolumn{4}{|c|}{ Self-transcendence } \\
\hline & $\bar{B}(\mathrm{SE})$ & $\mathrm{P}$ & $\Delta \mathrm{R}^{2}(\%)$ & $\mathrm{R}^{2}$ & $\overline{\mathrm{B}(\mathrm{SE})}$ & $\mathrm{P}$ & $\Delta \mathrm{R}^{2}(\%)$ & $\mathrm{R}^{2}$ & $\overline{\mathrm{B}(\mathrm{SE})}$ & $\mathrm{P}$ & $\Delta \mathrm{R}^{2}(\%)$ & $\mathrm{R}^{2}$ \\
\hline Mother & & & $5.2^{\mathrm{a}}$ & $5.2^{\mathrm{a}}$ & & & $3.8^{\mathrm{a}}$ & $7.2^{\mathrm{a}}$ & & & $<0.1^{\mathrm{a}}$ & $5.9^{\mathrm{a}}$ \\
\hline Hostile rearing & $-0.16(0.03)$ & $<0.01$ & 2.2 & 2.2 & $-0.14(0.03)$ & $<0.01$ & 1.9 & 5.3 & $0.02(0.03)$ & 0.46 & $<0.1$ & 5.9 \\
\hline Unhealthy habits & $-0.13(0.03)$ & $<0.01$ & 1.2 & 1.2 & $-0.10(0.03)$ & $<0.01$ & 0.8 & 4.2 & $0.00(0.03)$ & 0.92 & $<0.1$ & 5.8 \\
\hline Dissatisfaction & $-0.21(0.05)$ & $<0.01$ & 1.8 & 1.8 & $-0.21(0.05)$ & $<0.01$ & 1.8 & 5.2 & $-0.01(0.05)$ & 0.79 & $<0.1$ & 5.8 \\
\hline Family SES & $0.11(0.03)$ & $<0.01$ & 1.1 & 1.1 & $0.05(0.03)$ & 0.10 & 0.2 & 3.6 & $-0.06(0.03)$ & 0.05 & 0.3 & 6.2 \\
\hline Age at childbirth & $0.01(0.01)$ & 0.02 & 0.4 & 0.4 & $0.01(0.01)$ & 0.02 & 0.5 & 3.9 & $0.00(0.01)$ & 0.51 & $<0.1$ & 5.9 \\
\hline Father & & & $2.4^{\mathrm{b}}$ & $2.4^{\mathrm{b}}$ & & & $1.0^{\mathrm{b}}$ & $4.4^{\mathrm{b}}$ & & & $0.2^{\mathrm{b}}$ & $6.1^{\mathrm{b}}$ \\
\hline Unhealthy habits & $-0.09(0.03)$ & $<0.01$ & 0.8 & 0.8 & $-0.07(0.03)$ & 0.01 & 0.5 & 3.9 & $-0.03(0.03)$ & 0.32 & $<0.1$ & 5.9 \\
\hline Dissatisfaction & $-0.13(0.04)$ & $<0.01$ & 0.7 & 0.7 & $-0.09(0.04)$ & 0.03 & 0.4 & 3.8 & $-0.02(0.04)$ & 0.64 & $<0.1$ & 5.8 \\
\hline Age at childbirth & $0.01(0.01)$ & 0.27 & $<0.1$ & $<0.1$ & $0.01(0.01)$ & 0.17 & 0.1 & 3.5 & $0.00(0.01)$ & 0.63 & $<0.1$ & 5.8 \\
\hline
\end{tabular}

Note. $\mathrm{R}^{2}=$ adjusted $\mathrm{R}^{2}, \Delta \mathrm{R}^{2}=$ change in adjusted $\mathrm{R}^{2}$ compared to the model with only sex and birth year

B coefficients are reported for separate regression models, adjusted for sex and birth year

Mother and father share the same family SES 
${ }^{a} R^{2}$ and change in $R^{2}$ compared to the model with only sex and birth year: all maternal characteristics and family SES in the same multiple regression model

${ }^{b} R^{2}$ and change in $R^{2}$ compared to the model with only sex and birth year: all paternal characteristics and family SES in the same multiple regression model 


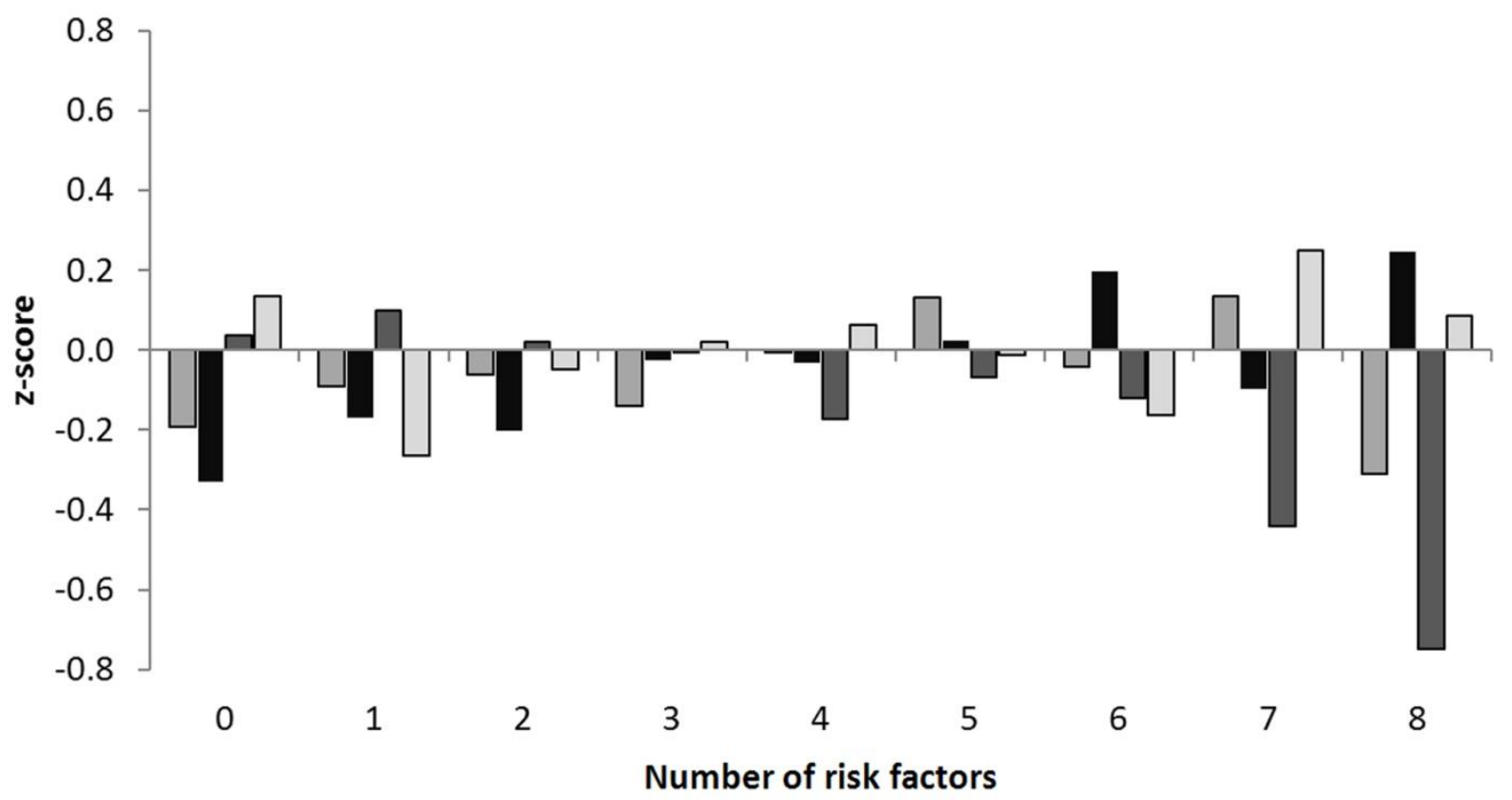

$\square$ Novelty Seeking $\quad$ Harm Avoidance $\quad \square$ Reward Dependence $\quad \square$ Persistence

Figure 1 


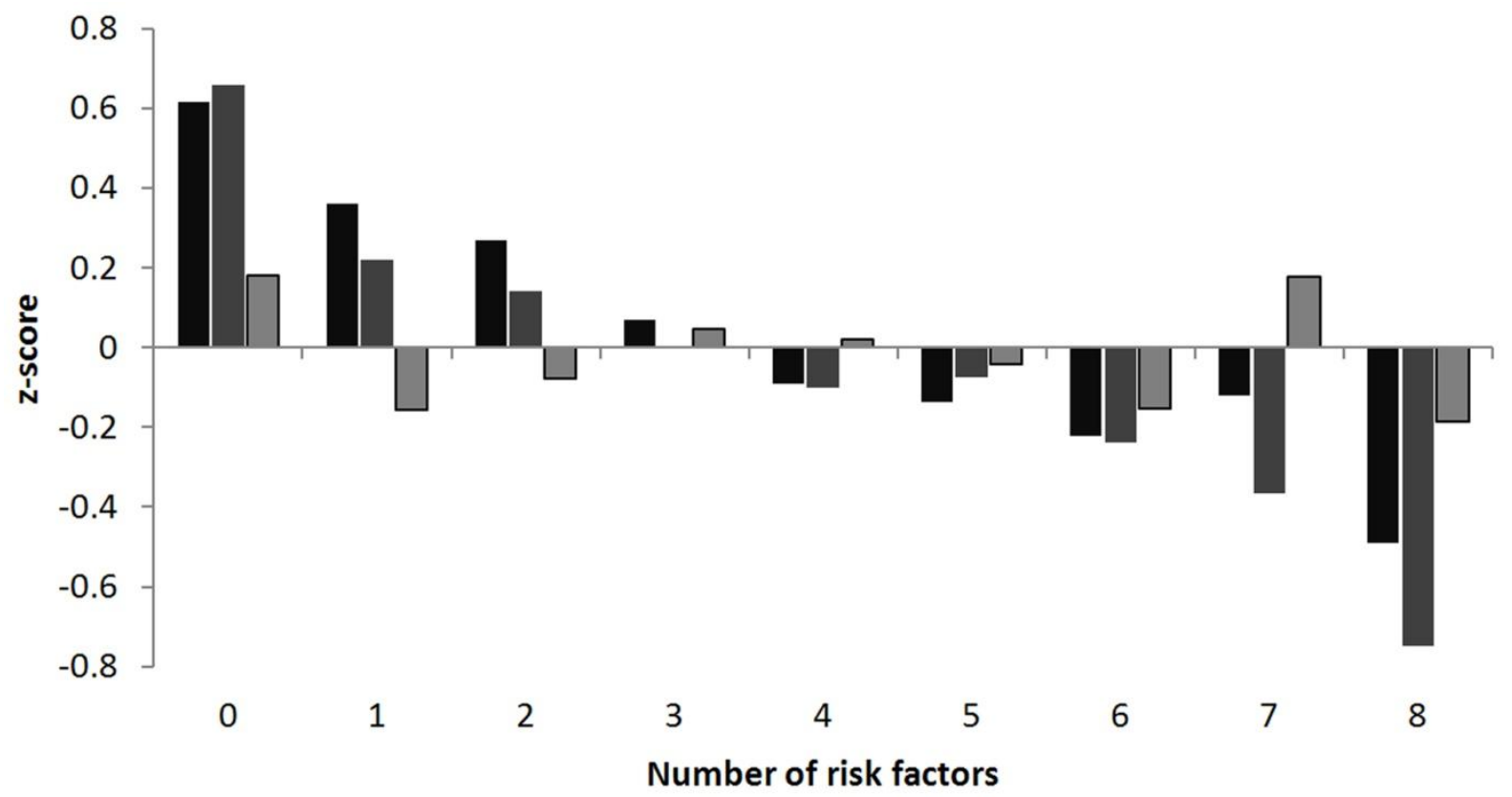

- Self-directedness $\square$ Cooperativeness $\square$ Self-transcendence

Figure 2 